\title{
The production of a machine designed for the cold radial cyclic forging of solid and tube billets
}

\author{
A. P. Karamyshev ${ }^{1,2}$, I. I. Nekrasov ${ }^{1,2}$, V. S. Parshin ${ }^{1,2}$, \\ O. O. Podolyak ${ }^{1,2}$, A. A. Fedulov ${ }^{1,2}$, A. I. Dronov ${ }^{1,3}$, V. A. Horev ${ }^{1,3}$, \\ A. I. Pugin ${ }^{2}$, A. V. Serebryakov ${ }^{3}$, K. B. Potyrin $^{4} \&$ A. A. Artemkin ${ }^{4}$ \\ ${ }^{1}$ Ural Federal University, Russia \\ ${ }^{2}$ NTP "RadialPro", Russia \\ ${ }^{3}$ Pervouralsk New Pipe Plant JSC (PNTZ), Russia \\ ${ }^{4}$ JSC "UralNINI", Russia
}

\begin{abstract}
This paper gives an account of a new project for the design and production of a radial cyclic forging machine. This new design considers the advantages of its predecessor and of modern trends within the engineering industry. The use of this machine could enable the considerable reduction of production wastes. Besides the cold cyclic technology implemented in this machine, it will also allow for the increase in energy efficiency, for the minimum capital investments. Keywords: metallurgy, technology, radial forging, radial-forging machine, billet, hardly-deformed alloys, tungsten heavy alloys, pipe, drawing, energy saving.
\end{abstract}

\section{Urgency of the topic and the demand for development}

Currently, one of the main problems with steel production is the fact that it is energy intensive. This fact directly affects the enterprise, the product efficiency and its competitiveness and this is why the development of technology and metal forming machines is so relevant today $[1,2]$. This machine must be able to perform operations of production from various alloys; this provides the lowest production cycle and minimization of energy consumption [3]. 


\section{Background of the project}

The purposes of this project were:

1. To create a modern, high-performance and cost-effective technology for cold radial cycling forging of solid and tube billets, made from different steels and alloys (including hardly-deformed);

2. To create machines and mechanisms for the implementation of this technology.

This technical project for designing a special machine for cold radial cyclic forging of solid and tube billets and the industrial prototype for testing at the plant was engineered by the staff at "Metallurgical and Rotary Machines" and "Organizations of Machine-building Production" in co-operation with the small-scale innovation enterprise "NTP "RadialPro" (Ekaterinburg), JSC "PNTZ" (Pervouralsk) and JSC "UralNINI" (Ekaterinburg).

\section{The special machine for cold radial cyclic forging}

The unique quality of the project results here is that the radial-forging machine design allows us to conduct processes of blanks compression without their prior heating. The next item of uniqueness is the trajectory of movement for the forging tools. This technological capability is especially important when the hot deformation of work pieces is undesirable or absolutely impossible. The exclusion of an initial heating operation leads to considerable savings on energy costs and directly affects the efficiency of the production line.

The next important feature of the machine is its ability to carry out large single reductions per billets without their fracture. This technological opportunity provides a significant decrease in the duration of the technological processing cycles and as a consequence will save energy.

The radial-forging machine can be applied, industrially, to the production of high-technology and more specifically, using high-precision heat-exchange pipes made from corrosion-resistant steel with the raised requirements.

For pipe preparation before any dragging it is necessary to reduce the front end (hook) pipe diameter for the delivering stage [4]. The physical and mechanical properties of the steels and their deformation characteristics define the preparation technology for such pipes and define the necessary equipment.

The specifications for the quality of the pipe cogged part should $[5,6]$ :

- allow two or three times dragging without additional compression of the tube hook;

- have enough strength for the breaks excluding the process during capture and dragging;

- have a smooth transition from a hook to the pipe body;

- do not have axled torsion.

The length of the tube hook depends on the:

- billet pipe diameter;

- the thickness of the pipe wall; 
- construction of the dies fastening;

- the gripping device construction of the dragging.

After the necessary dragging operations the tube hook has to be removed. If the technology includes dragging, total losses of the metal are about $33 \%$ of the metal output. The metal wastes by removing the hooks are about $20-40 \%$ of the total wastes or about $13.5 \%$ pre 1 tonne of the finished tubes $[7,8]$. Thus, the problem of the production of qualitative pipe hooks and the minimization of the material wastes is relevant and requires the effective equipment development for its decision. Hence, the small scale enterprise "NTP RadialPro" set the task to design the construction of a radial forging machine for preparing pipe hooks for dragging. This machine must fulfill the requirements of the customer - JSC "PNTZ". The conducted scientific research allows us to produce a radial cyclical forging machine. The machine has been produced on the "UralNITI" plant. There are three main items of equipment, which are unique within this field:

- $\quad$ the working mechanism, which consists of four tools (peens);

- the unique electromechanical drive, which is employed in the machine;

- a special feed device, with which the machine is equipped (figs. 1 and 2).

The main unit of the machine is the forging component. The forging unit stand is designed as a closed welded box. The converting mechanism is placed in the internal cavity of the stand. This converting mechanism provides the transformation from rotary movement to the four levers oscillatory movement. The levers rotation axes are placed in the forging unit stand. At the end of the lever the working tools (the peens) are fixed with the use of eccentric sleeves. Simultaneous complex movement of the peens from the periphery to the center corresponds to a circular arc. Such motion path of a tool provides $[9,10]$ :

- a favorable deformation scheme;

- a large degree of deformation;

- the rational use of deformation force.

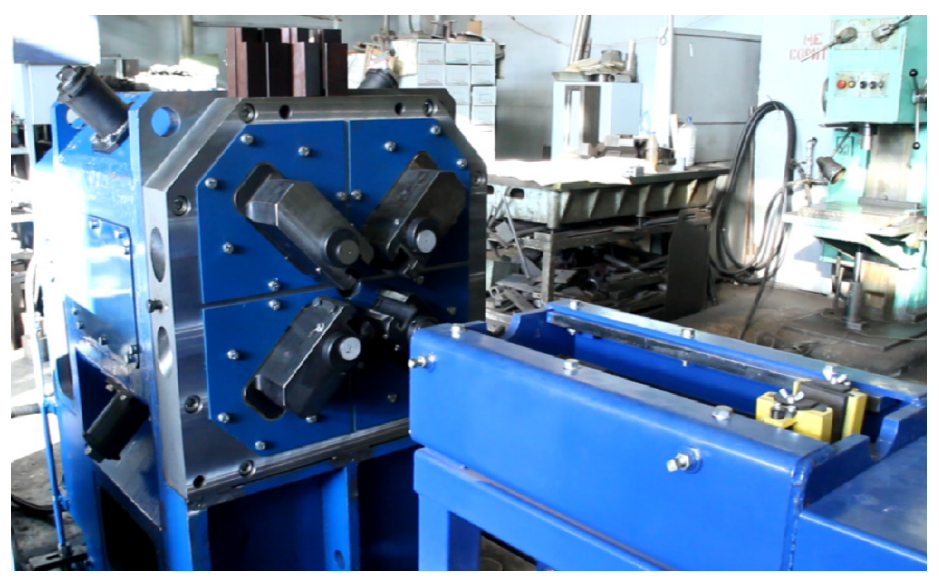

Figure 1: The machine with the feeder. 


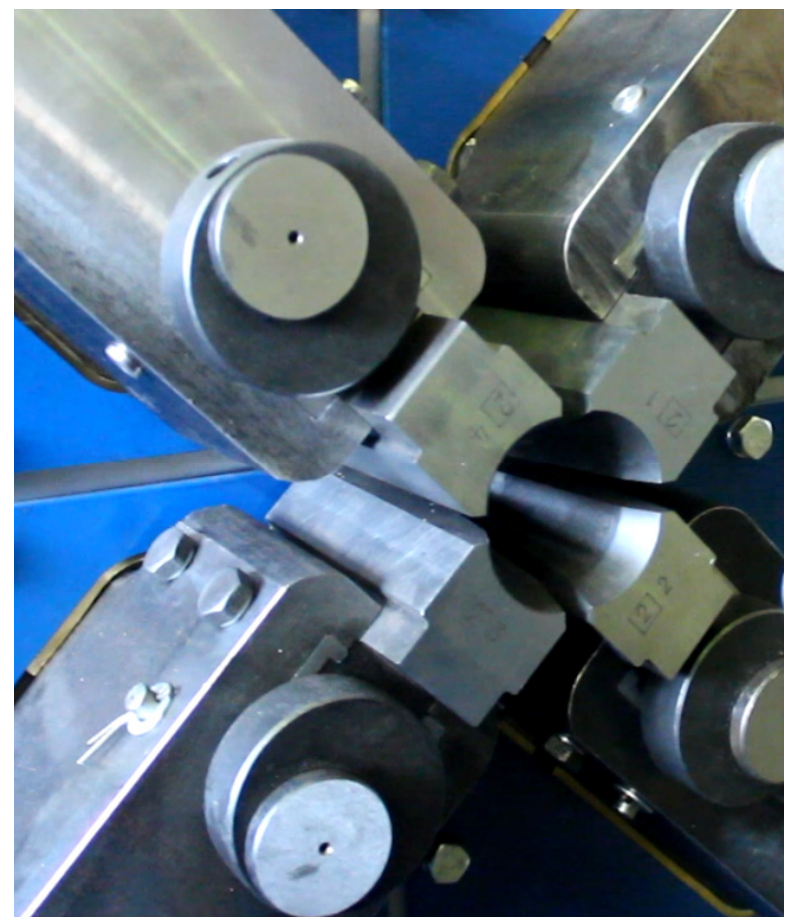

Figure 2: $\quad$ The working tools (peens).

All of these characteristics increase the resistance of the working tool. This simple and easy-to-handle working tool allows for the machine to fix different types of billets (different sizes of billets), with a cost minimization for changeovers. The work-piece length (which has to be reduced) is determined by the special stop position inside the machine. The machine is equipped with an automatic circulation lubrication system for greasing the friction.

\section{Additional using of the machine in the technological processes}

The radial-forging machine has an industrial application in the production of high-technology; high-precision heat-exchange pipes with the raised requirements made from the corrosion resistant steels $[11,12]$. In addition, the department of "Metallurgical and Rotary Machines" created the technology for manufacturing the wire made from special aluminium alloys. This technology provides unique properties to the final product with a significant reduction of the production cycles. Aluminium alloys are hardly deformed despite their initially high plasticity. Currently used technology is based on a multi-transition process of the extruded rods (billets) dragging. This technology has some significant drawbacks, as detailed in the following. 
1. This technology can provide the small diameter of a rod obtained after compression, which leads to the inefficient functioning of press equipment. These sizes are determined by limited technological possibilities of the dragging equipment and the process's possibility. For example, the process allows only one assumptive value of the broach between production phases (about 1.9-2.2 for these materials) without obligatory intermediate annealing. The described situation leads to the use of a multitransition process and to higher energy and labor costs. Multitransition dragging also leads to the accumulation of inadmissible surface defects, which can lead to material losses.

2. The second important factor is that the main parameter that determines the properties of the rivet wire service is equal to the metal grain size. The decrease of the metal grain size provides a higher level of physical and mechanical properties and at the same time this task is extremely difficult when dragging technology is used [1,4]. For the achievement of high set properties it is necessary to obtain a small-grained structure. It is practically impossible to reach this goal when dragging is used.

This new technology is based on the radial cyclic forging machine used for cold deformation of the rod. When such technology and machinery are used, the diameter of the work-piece is increased by 3 times and the mode of cobbing provides 9 fold exhaustion (88\%) in two production phases without intermediate annealing. Dragging operation is used only in the final cycle of processing, mainly as a finisher. This technology provides more than twice the grain pounding and as a consequence obtains high physical and mechanical properties of the finished products. As a result, the implementation of new technology can significantly reduce energy consumption in the manufacture of wire.

Substantial energy savings and a significant reduction in the expensive material losses were obtained in the developed process of the composite tungsten alloys deformation hardening. This technology was enabled by the "Metallurgical and Rotary Machines" organisation.

Currently, the main method for the hardening of alloys is hydro-pressing (hydro-shaping). The deformation degree maximum during the hydro-extrusion may reach $25-33 \%$ by cold processing and $35-45 \%$ by warm processing. To realize a large cross-sectional change it is necessary to use an intermediate annealing between the passes. It is important that there is an increased consumption of processed material related to the technology of the process. A significant drawback of the hydroforming is that with the use of the hardening method the stability of the physical-mechanical properties of the blank is not achieved.

\section{Conclusion}

The developed technology of hardening by use of a cyclic compression machine:

1. provides high compression for passage - up to $70 \%$ by cold processing; 
2. significantly reduces the required degree of deformation to $28-30 \%$ in order to achieve a given level of physical and mechanical properties;

3. can significantly reduce the residual value of the tangential exertion;

4. provides uniformity distribution of the tangential along the length of the work-piece;

5. provides an increase of the material utilization by $25-30 \%$.

Overall, the designed machine provides the equipment for the plastic deformation of various alloy billets, one of the main indicators of which is a high level of energy efficiency and economy of materials, which minimizes the spoilage and improves the quality of the final product.

\section{References}

[1] Lubvin V.I. Radial forging metal processing. Moscow: Engineering, p. 248, 1975.

[2] Pertsikov Z.I. Drawing mill 3. И. Перциков. Moscow: Metallurgy, p. 208, 1986.

[3] Bisk M.B., Grekhov I.A., Slavin V.B. Cold deformation of steel pipes: P.1. Preparation for deformation and drawing. Sverdlovsk: Sredne-Ural Publ., p. 232, 1976.

[4] Turin V.A., Lazorkin V.A., Pospelov I.A., Flakhovskiy G.P. Forging process and equipment. Moscow: Engineering, p. 256, 1990.

[5] Karpov S.M. Osadchii V.Ya., Lamin A.B. Determination of force parameters of the pipes ends forging process before drawing // Steel. № 11. pp. 70-71, 2000 .

[6] Klempert E.D., Golubchick R.M., Uschveridze K.E. Experimental study of the pipes ends forging process before drawing // Steel. № 1. pp. 61-63, 2002.

[7] Karamyshev A.P., Nekrasov I.I., Parshin V.S., Pugin A.I. Finding an efficient shape for the cross section of the front end of a tubular semifinished product to perform drawing, Springer New York, Volume 55, Numbers 3-4, pp. 274-277, 2011.

[8] Karamyshev A.P., Nekrasov I.I., Parshin V.S., Systerov V.A Using an AVS radial-forging machine to prepare the ends of tubes for drawing, Springer New York, Volume 52, Numbers 9-10, pp. 498-500, 2008.

[9] Karamyshev A.P., Nekrasov I.I., Parshin V.S., Systerov V.A Determination of the active forces in the reduction of semifinished products on AVS radial forging machine, Springer New York, Volume 53, Numbers 3-14, pp. 162-166, 2009.

[10] Parshin V.S., Nekrasov I.I., Pugin A.I., Fedulov A.A., Dronov A.I., Horev V.A., Serebryakov A.V., Potyrin K.B., Artemkin A.A. Working out the technology and the machine for preparation pipes hooks, which are made from corrosion-resisting steel, for dragging, Modern metal materials and technologies, the tenth international scientific and practical conference, S. Petersburg, pp. 343-345, 2013. 
[11] Karamyshev A.P., Nekrasov I.I., Parshin V.S., Pugin A.I., Fedulov A.A. Modeling metal-shaping operation in Deform-3D in order to efficiently design production processes, Springer New York, Volume 56, Numbers 1-2, pp. 116-118, 2012.

[12] Karamyshev A.P., Nekrasov I.I., Parshin V.S., Pugin A.I., Fedulov A.A. Study of transients in metal-shaping, Springer New York, Volume 53, Numbers 9-10, pp. 623-626, 2009. 